1508

CHAN

C. 3

An All New

Natural History Experience
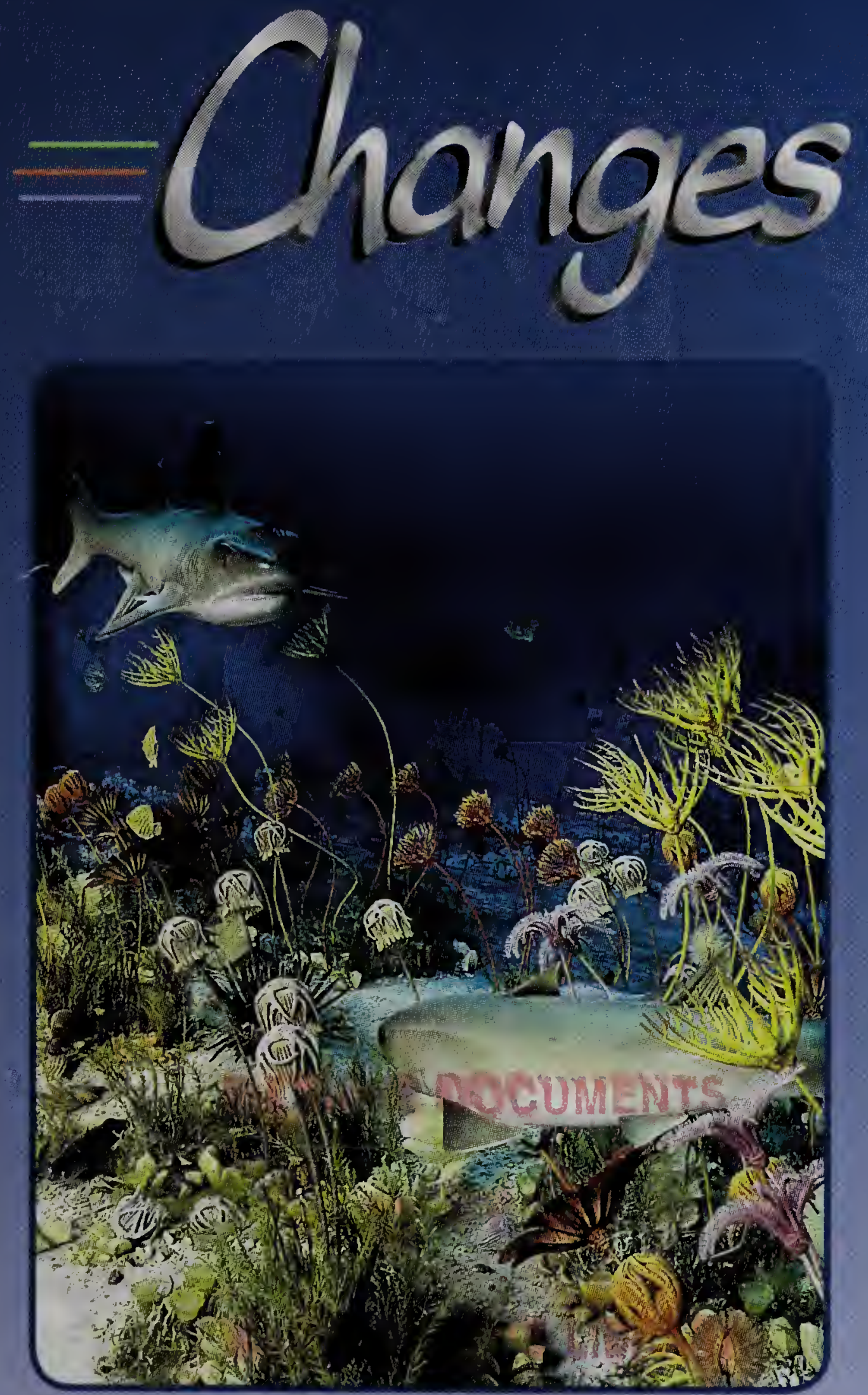

Join the staff of

the Changes Institute to explore environmental change in Illinois

$$
56189616
$$

ILLINOIS - STATE - MUSEUM 


\section{Introduction-Join the Team!}

- Use your free identification card to access interactive exhibits.

- Get to know scientists who study climate, land, and life in the Meet the Team videos.

- Discover how scientists read geological, biological, and human evidence of change.

- Witness the awesome forces of change in our Earth Forces video.

\section{Tropical Illinois-Underwater}

- Dive in! Encounter the giant sharks and fish that swam in shallow seas when Illinois was close to the equator.

- Match fossils to animals in a 340 million year old Mississippian sea.

- Become a Devonian shark and catch your lunch in the Shark Attack video game.

\section{Tropical Illinois-Land}

- See fern-like trees, giant dragonflies. and large amphibians in a Coal Age tropical forest of 320 million years ago.

- Examine plant and animal fossils from uplands, swamps, and seas.

- Learn how fossils and coal formed.

- Walk through a fluorite mine lined with spectacular crystals of the State mineral.

\section{Missing Pieces}

- See fossil leaves from the Age of Dinosaurs.

- Learn why the Hall of Illinois Dinosaurs is empty! 


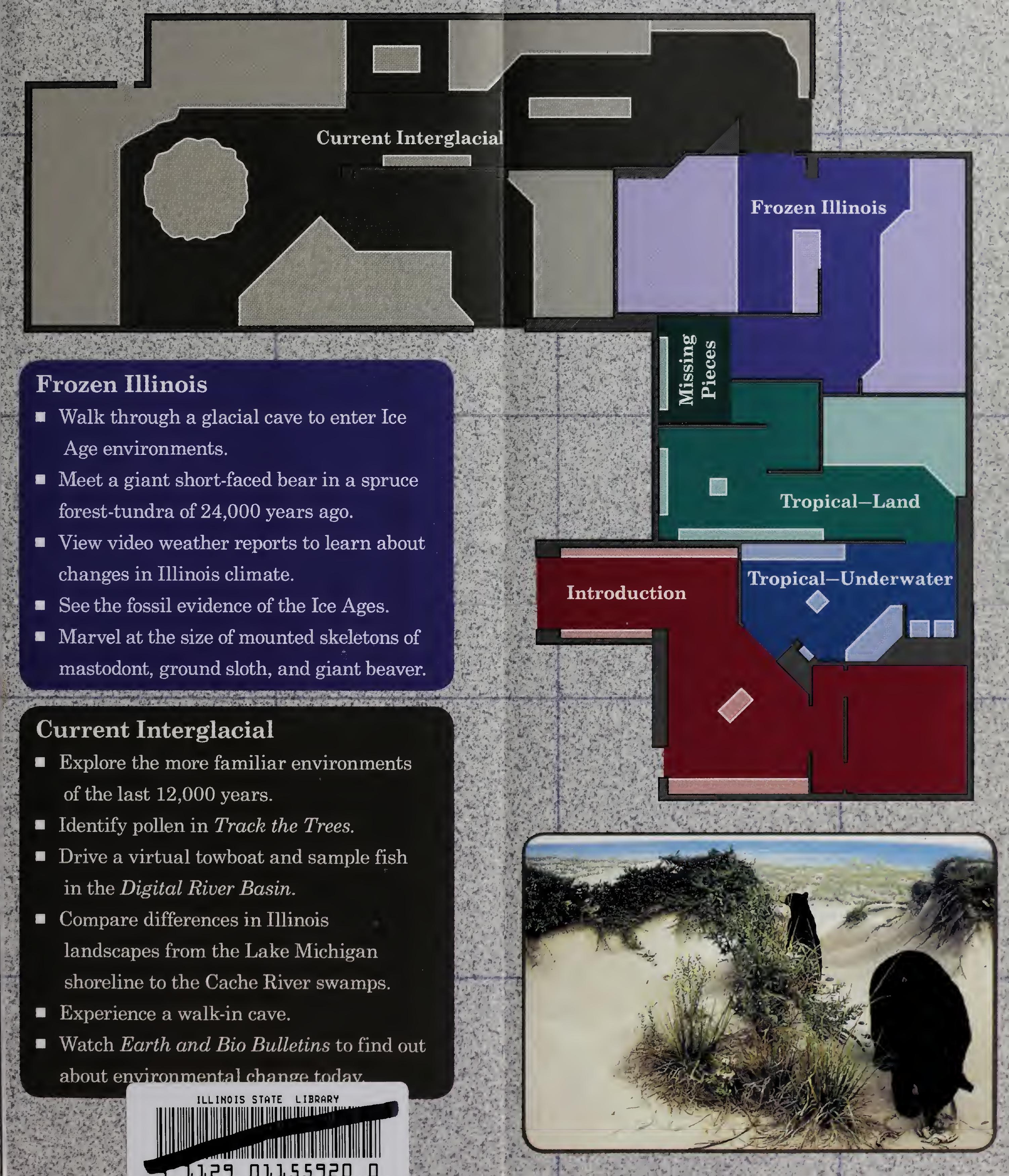



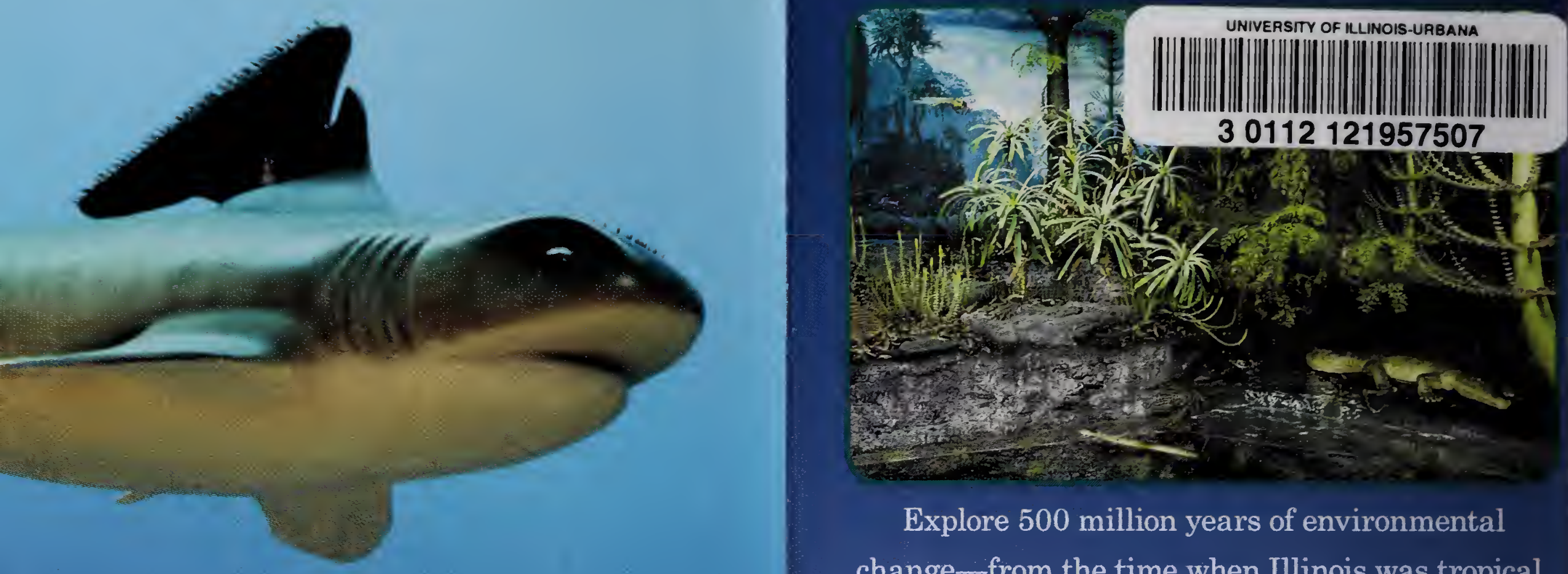

Explore 500 million years of environmental change-from the time when Illinois was tropical, through the Ice Ages, to the diverse landscapes of the modern era.

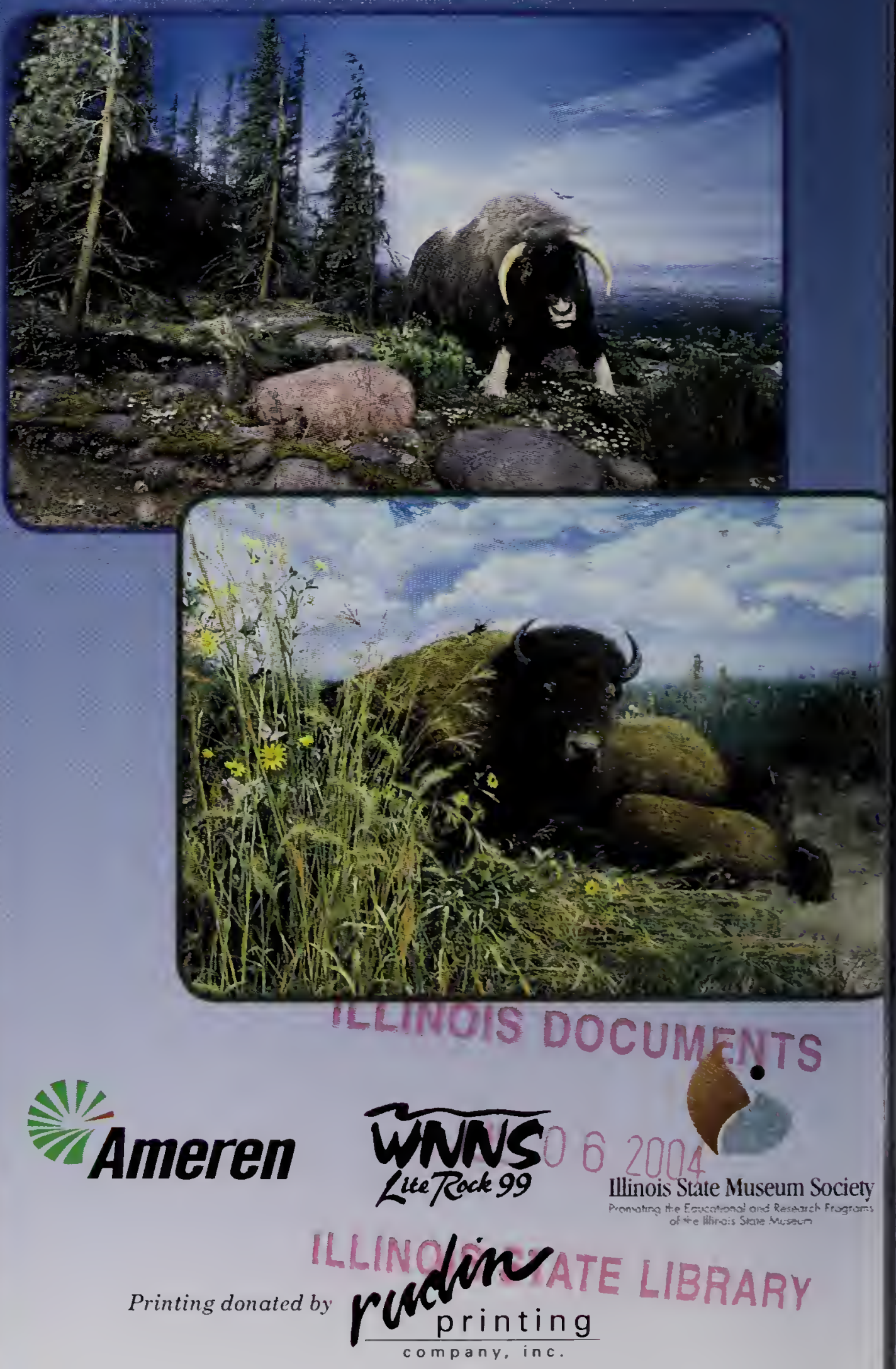

